\title{
Reliability and Validity of the Center for Epidemiologic Studies Depression (CES-D) Scale for Adolescents in Lao PDR
}

\section{Sachi Tomokawa ${ }^{1,2^{*}}$, Takashi Asakura ${ }^{2,3}$, Ngouay Keosada ${ }^{4}$, Vannasouk Bouasangthong4, Vanthala Souvanhxay ${ }^{4}$, Kethsana Kanyasan ${ }^{4}$, Kimihiro Miyake1, Sithane Soukhavong4, Khamseng Thalangsy ${ }^{4}$, Kazuhiko Moji ${ }^{5}$}

${ }^{1}$ Department of Sports and Health Sciences, Faculty of Education, Shinshu University, Nagano, Japan

${ }^{2}$ Japanese Consortium for Global School Health and Research, University of the Ryukyus, Okinawa, Japan

${ }^{3}$ Department of Education, Tokyo Gakugei University, Tokyo, Japan

${ }^{4}$ Faculty of Education, National University of Laos, Vientiane, Lao PDR

${ }^{5}$ School of Tropical Medicine and Global Health, Nagasaki University, Nagasaki, Japan

Email: *sachitjp@shinshu-u.ac.jp

How to cite this paper: Tomokawa, S., Asakura, T., Keosada, N., Bouasangthong, V., Souvanhxay, V., Kanyasan, K., Miyake, K., Soukhavong, S., Thalangsy, K., \& Moji, K. (2020). Reliability and Validity of the Center for Epidemiologic Studies Depression (CES-D) Scale for Adolescents in Lao PDR. Psychology, 11, 1646-1660. https://doi.org/10.4236/psych.2020.1111104

Received: October 1, 2020

Accepted: November 14, 2020

Published: November 17, 2020

Copyright $\odot 2020$ by author(s) and Scientific Research Publishing Inc. This work is licensed under the Creative Commons Attribution International License (CC BY 4.0).

http://creativecommons.org/licenses/by/4.0/ (c) (i) Open Access

\begin{abstract}
This study aimed to develop a Laotian adolescent version of the Center for Epidemiologic Studies Depression Scale (CES-D), determine its reliability and validity, and examine its factorial properties. The study targeted $7554 \mathrm{stu}-$ dents in lower secondary schools and teacher training colleges in Lao PDR. Self-administered questionnaires were distributed and collected from 2012 to 2014. Exploratory factor analysis was performed in three age groups using the weighted least square mean and variance adjusted estimation with robust maximum likelihood methods. The factor structure for each age group was the same; therefore, data from the full sample were analyzed further. The model was then tested by confirmatory factor analysis. A 2-factor model was determined as a common model among the age groups by using paralleled analysis. We determined a best-fitting structure comprising two factors: "Negative affect" and "Positive affect". The Cronbach's alpha was 0.81. "Effort" items loaded on the "Somatic and retarded activity" factor in the original model but loaded on the "Positive affect" factor in the adolescent model. "Depressed affect," "Somatic and retarded activity," and "Interpersonal" items were combined into the "Negative affect" factor in the adolescent model.
\end{abstract}

\section{Keywords}

Adolescents, Depression, CES-D, Laos, Psychometric Testing 


\section{Introduction}

One in six people are aged 10 - 19 years (World Health Organization, 2018). The World Health Organization (WHO) has advocated strengthening adolescent health as an important agenda for the next decade (World Health Organization, 2014). Mental health disorders commonly emerge during adolescence (Kessler et al., 2007a) and account for $16 \%$ of the global burden of disease and injury in individuals aged 10 - 19 years (World Health Organization, 2020). For example, depression is one of the leading causes of illness and disability among adolescents globally (World Health Organization, 2020). Further, previous researches have reported that half of all mental health disorders start by the mid-teens (Kessler et al., 2007a, 2007b). In order to prevent mental health disorders in adolescents, early detection and treatment are essential. However, children's and adolescents" mental health needs have been neglected, especially in low- and middle-income countries (Kieling et al., 2011).

Mental health disorders are emerging public health issues, especially in developing Asian countries. Nearly half of all people who have mental health disorders live in South-East Asia and Western Pacific regions (World Health Organization, 2017). Lao PDR is one of the least developed countries in South-East Asia; however, it is now undergoing rapid development, and thus drastic changes are affecting people's lifestyles. A previous study reported that these changes might give rise to physical and mental health disorders (Asakura et al., 2015). Physical, emotional, and social changes can affect mental health in adolescents (World Health Organization, 2020).

In Laos, the proportion of adolescents aged $10-19$ makes up $20 \%$ of the total population (Laos Statistical Information Service, 2019). Moreover, the net enrollment rate for secondary education in Laos, which was $27.4 \%$ in 2000 , improved to $60.0 \%$ in 2018 (World Bank, n.d.). Regarding the response to adolescents' health, including mental health disorders, the government of Laos expanded its target of school health activities from primary to secondary schools in its revised national school health policy (Ministry of Education \& Ministry of Health, Lao PDR, 2010). Moreover, the government of Laos added the importance of providing a healthy psychosocial environment in school as one of the components of the revised school health policy (Ministry of Education \& Ministry of Health, Lao PDR, 2010).

In this backdrop, social response to depression in Laotian adolescents has been required, and therefore, learning about depression and its influential factors such as economic development and lifestyle changes was incorporated into relevant teacher training curriculums in Laos in 2019 (Tomokawa et al., 2020). If mental health disorders such as anxiety and depression can be detected in its early stage by appropriate tools for depression, early interventions will reduce mental health risks. However, in Laos, less attention has been paid to depression, and there is a lack of appropriate tools to assess depression in adolescents.

Previous research with Laotian high school students estimated the prevalence 
of depression in a clinical setting (Phanthavong, Naphayvong, \& Reinharz, 2015). However, this study used the Beck Depression Inventory (Beck et al., 1961).

The Center for Epidemiologic Studies Depression Scale (CES-D) is a 20-item questionnaire designed to detect depression. The CES-D has been translated and used in many countries for epidemiological research. Radloff s original CES-D is composed of four factors: "Depressed affect", "Somatic and retarded activity," "Positive affect," and "Interpersonal" (Radloff, 1977). This instrument is one of the most frequently used scales to evaluate depressive symptomatology in community samples. A study by Tomokawa developed a CES-D Laotian version and confirmed its validity and reliability (Tomokawa et al., 2018). However, that Laotian version has only been examined with adult population samples, and thus, its applicability to other age groups is unknown.

There are various versions of the CES-D for adolescents, and the factor structures of the developed models have been tested. Results have indicated that the factor structure and number of factors differ among the developed CES-D models. For example, research on factor analysis with Filipino American adolescent samples reported two-factor solutions (Edman et al., 1999). However, studies on Native American Indian adolescents (Dick, Beals, Keane, \& Manson, 1994), Chinese American adolescents (Yen, Robins, \& Lin, 2000), mainland Chinese adolescents (Wang et al., 2013), Malaysian adolescents (Ghazali, Elklit, Balang, \& Chen, 2016), and Chinese and Korean adolescents (Heo, Choi, Yu, \& Nam, 2018) have reported three-factor solutions. Four-factor solutions were found in studies with Anglo-American and Mexican American youths (Crockett et al., 2005), young Chinese children (Li, Chung, \& Ho, 2010), and Taiwanese adolescents (Cheng, Yen, Ko, \& Yen, 2012). A five-factor structure was reported in a study with Chinese American college students (Ying et al., 2000). These differences in the number of factors may indicate differences in mental health characteristics across countries and cultures. However, a CES-D for Laotian adolescents has not yet been developed. Thus, it is necessary to develop a CES-D for Laotian adolescents. Therefore, this study aimed to develop a CES-D for Laotian adolescents, investigate its reliability and validity, and examine its factorial properties.

\section{Materials and Methods}

\subsection{Participants}

This study was conducted in Lao PDR from 2012 to 2014. Participants of this study consisted of college students (grades 1 to 4) from two teacher training colleges and secondary school students (grades 2 to 7 ) from ten secondary schools (Table 1).

In the selection of survey areas, we firstly took stock of the eight areas where teacher training colleges were located, and then, selected three prefectures whose population size and economic size were almost the same, namely, prefectures of Luang Prabang, Savannakhet and Champasak. These prefectures had the largest 
Table 1. Information of target schools.

\begin{tabular}{ccc}
\hline Target schools & Prefecture & Area \\
\hline Teacher Training College A & Luang Prabang & North \\
Secondary school A & & \\
Secondary school B & & \\
Secondary school C & & \\
Secondary school D & Savannakhet & South- \\
Secondary school E & & \\
Secondary School F & & \\
Teacher Training College B & Champasak \\
Secondary School G & & \\
Secondary School H & & \\
Secondary School I & & \\
Secondary School J & & \\
\hline
\end{tabular}

population and economic scale after the Vientiane municipality where is the capital city of Laos. After that, we selected secondary schools which were located nearby the teacher training colleges in the selected three prefectures.

\subsection{Research Process and Research Tools}

In this study, we requested cooperation of teachers to conduct a questionnaire survey in their schools, taking the opportunity of in-service teacher trainings organized by our research team. We provided the teachers with guidance about the survey including the survey purpose and potential risks and benefits. Then, the teachers communicated the information and instruction about the survey to the school directors and classroom teachers in their schools so as to obtain their approval for the survey. In the implementation of the survey, classroom teachers, who were in charge of the implementation, preliminarily informed targeted students that participation was voluntary; that participants would be free to withdraw from the survey at any time; and, that participation in the survey was not related to school performance evaluation. Written informed consent was obtained from the students before the implementation.

Participant students evaluated their mental health situation in the past week with a self-administered questionnaire-the Laotian CES-D for adolescentswhich was developed by modifying the existing Laotian CES-D for adults (Tomokawa et al., 2018). The CES-D for Laotian adolescents includes 20 items, each rated on a 4-point Likert scale. Four items are reverse scored. In the development of the Laotian CES-D for adolescents, items relating to the factors that were excluded in a previous study on the Laotian CES-D for adults- "Bothered," "As good," "Keeping mind," "Effort," and "Unfriendly"-were modified in terms of translation between Laos and English to employ phrases that better matched the intended meanings of the items. 
Ethical approval was obtained from the Committee of Tokyo Gakugei University (No. 227) and the National Ethics Committee for Health Research in Lao PDR (No. 172). We commenced the research with the agreement of the Ministry of Education and Sports in Lao PDR and the National University of Laos.

\subsection{Statistical Analysis}

Data were analyzed using SPSS (Version 21.0) and Mplus (8.3). The statistical significance was set at $p<0.05$. Cronbach's alpha coefficient was calculated, and the internal consistency and item homogeneity were evaluated.

There are several different definitions of the age range of adolescents. The WHO defines "very young adolescents" as children aged 10 - 14 years (World Health Organization, n.d.), “adolescents" as individuals aged 10 - 19 years, and "youth" as those aged 15 - 24 years (World Health Organization, 2014). The United Nations Children's Fund (UNICEF) applies the age range of 10 - 19 years to "adolescents," and the adolescent population is divided into two groups in the UNICEF definition: early adolescence (10 - 14 years) and late adolescence (15 19 years) (United Nations Children's Fund, 2011). Meanwhile, a previous study defined adolescence with an age range of 10 - 24 years that corresponds more closely to adolescent developmentthan 10 - 19 years (Sawyer, Azzopardi, Wickremarathne, \& Patton, 2018). In the Laotian education system, secondary school starts at the age of 11; therefore, we excluded students who were under 10 years and who did not provide the information about gender and age in the analysis of this study. Therefore, in this study, we targeted students aged 11 - 24 years and defined this age group as "adolescent." Further, in statistical analyses, we divided the data into three age groups, namely, early adolescence (11 - 14 years), late adolescence (15 - 19 years), and young adulthood (20 - 24 years), and analyzed the data of each group separately, and then aggregated the sample data (11 - 24 years).

First, we performed exploratory factor analysis (EFA) for each age group, using the weighted least square mean and variance adjusted estimation. Considering the resulting eigenvalues and the interpretability of factors, we identified a three-factor model. However, the early adolescents' model differed in model structure from those for the other two age groups. Therefore, we then performed a parallel analysis to determine the number of factors in each age group. Based on this analysis results, we suspected that the number of factors was two in all age groups. Then, we conducted EFA and confirmed that all groups had a twofactor structure. Next, multi-group analysis (11 - 14 years, 15 - 19 years, and 20 24 years) was performed using a two-factor structure as a configurable model. In the multi-group analysis, we examined whether the factor structure, that is, the number of factors and the factor loading patterns of the items related to the factors, was the same. Based on the result of the multi-group analysis, we determined that a two-factor model was common among age groups. The two-factor model for the aggregated data from all three groups was tested with confirmato- 
ry factor analysis (CFA) using the weighted least square mean and variance adjusted estimation.

Model fit was evaluated with a chi-square test, root mean square error of approximation (RMSEA), standardized root mean square residual (SRMR), and comparative fit index (CFI). RMSEA values less than 0.05 indicate a good fit, and values as high as 0.08 represent acceptable errors of approximation in the population (Browne \& Cudeck, 1993). RMSEA values ranging from 0.08 to 0.10 indicate a moderate fit, and values greater than 0.10 indicate a poor fit. A value of less than 0.08 is generally considered a good fit ( $\mathrm{Hu} \&$ Bentler, 1999). Values for CFI range from 0 to 1.00 , with values greater than 0.95 considered representative of a good model fit (Bentler, 1990).

\section{Results}

\subsection{Participant Characteristics}

Data were collected from 7554 students (aged 11 - 24 years), of whom 3391 (44.9\%) were males and 4163 (55.1\%) were females. The average age of the total sample was $17.8 \pm 2.7$ years; the average age was $18.0 \pm 2.8$ for males and $17.7 \pm$ 2.6 for females. The number of participants in each age group was $789(10.4 \%)$ for the early adolescents (11 - 14 years), 4631 (61.3\%) for the late adolescents (15 - 19 years), and 2134 (28.2\%) for the young adults (20 - 24 years). Table 2 shows participants' characteristics by prefecture.

\subsection{Descriptive Statistics}

Table 3 shows the means and standard deviations for the developed CES-D for adolescents by age group and the aggregated sample.

\subsection{Factor Structure of the Laotian CES-D for Adolescents}

\subsubsection{Results of EFA by Age Group}

Table 4 shows the results of EFA by age group. We decided upon a three-factor model for all three age groups. However, the factor structure for early adolescents differed from that for the other two age groups. Factor 1 in the model for early adolescents included five items, while Factor 1 for late adolescents and young adults included 12 items. Similarly, Factor 2 in the model for early adolescents

Table 2. Participants' characteristics.

\begin{tabular}{|c|c|c|c|c|c|c|c|c|}
\hline \multirow{2}{*}{$\begin{array}{c}\text { Prefecture } \\
\text { Luang }\end{array}$} & \multirow{2}{*}{$\begin{array}{l}\text { Area } \\
\text { North }\end{array}$} & \multirow{2}{*}{$\begin{array}{c}\text { Gender } \\
\text { Male }\end{array}$} & \multicolumn{2}{|c|}{ Number } & \multicolumn{2}{|c|}{$\%$} & \multicolumn{2}{|c|}{ Age } \\
\hline & & & 1148 & 2700 & 42.5 & 35.7 & $19.4 \pm 2.6$ & $19.0 \pm 2.6$ \\
\hline Prabang & & Female & 1552 & & 57.5 & & $18.7 \pm 2.4$ & \\
\hline \multirow[t]{2}{*}{ Savannakhet } & South-central & Male & 648 & 1419 & 45.7 & 18.8 & $17.8 \pm 1.6$ & $17.5 \pm 1.5$ \\
\hline & & Female & 771 & & 54.3 & & $17.3 \pm 1.4$ & \\
\hline \multirow[t]{2}{*}{ Champasak } & South & Male & 1595 & 3435 & 46.4 & 45.5 & $17.0 \pm 2.8$ & $16.9 \pm 2.9$ \\
\hline & & Female & 1840 & & 53.6 & & $16.9 \pm 2.9$ & \\
\hline
\end{tabular}


Table 3. Means and standard deviations of the developed CES-D for adolescents for each age group and the aggregated sample.

\begin{tabular}{|c|c|c|c|c|c|c|c|c|}
\hline \multirow{2}{*}{ Item } & \multicolumn{2}{|c|}{$\begin{array}{c}\text { Early Adolescents } \\
11-14 \text { years }\end{array}$} & \multicolumn{2}{|c|}{$\begin{array}{c}\text { Late Adolescents } \\
15-19 \text { years }\end{array}$} & \multicolumn{2}{|c|}{$\begin{array}{l}\text { Young Adults } \\
20-24 \text { years }\end{array}$} & \multicolumn{2}{|c|}{$\begin{array}{l}\text { Aggregated sample } \\
\text { (11 - 24 years })\end{array}$} \\
\hline & Mean & $S D$ & Mean & $S D$ & Mean & $S D$ & Mean & $S D$ \\
\hline 1. Bothered & 0.75 & 0.91 & 0.82 & 0.87 & 0.91 & 0.89 & 0.84 & 0.88 \\
\hline 2. Poor appetite & 0.80 & 0.90 & 0.92 & 0.92 & 0.84 & 0.90 & 0.89 & 0.91 \\
\hline 3. Blues & 0.49 & 0.82 & 0.70 & 0.91 & 0.79 & 0.90 & 0.70 & 0.90 \\
\hline 4. As good & 1.50 & 0.97 & 1.34 & 0.92 & 1.19 & 0.89 & 1.32 & 0.92 \\
\hline 5. Keeping mind & 1.08 & 0.93 & 1.29 & 0.94 & 1.40 & 0.90 & 1.30 & 0.93 \\
\hline 6. Depressed & 0.74 & 0.90 & 1.03 & 0.96 & 1.19 & 0.93 & 1.04 & 0.96 \\
\hline 7. Effort & 1.79 & 1.04 & 2.02 & 0.98 & 2.31 & 0.87 & 2.08 & 0.97 \\
\hline 8. Hopeful & 0.78 & 0.95 & 0.57 & 0.83 & 0.30 & 0.66 & 0.52 & 0.82 \\
\hline 9. Failure & 0.91 & 0.97 & 1.26 & 1.00 & 1.43 & 0.94 & 1.27 & 0.99 \\
\hline 10. Fearful & 1.28 & 0.96 & 1.33 & 0.96 & 1.43 & 0.93 & 1.36 & 0.96 \\
\hline 11. Sleep & 0.90 & 0.98 & 1.06 & 0.99 & 1.19 & 0.96 & 1.08 & 0.98 \\
\hline 12. Happy & 0.56 & 0.96 & 0.57 & 0.93 & 0.55 & 0.90 & 0.56 & 0.92 \\
\hline 13. Talked less & 0.89 & 0.96 & 1.16 & 0.97 & 1.18 & 0.94 & 1.14 & 0.97 \\
\hline 14. Lonely & 0.79 & 0.97 & 1.07 & 0.99 & 1.17 & 0.97 & 1.07 & 0.99 \\
\hline 15. Unfriendly & 0.75 & 0.91 & 0.86 & 0.96 & 0.80 & 0.93 & 0.83 & 0.94 \\
\hline 16. Enjoyed & 0.82 & 0.87 & 0.93 & 0.88 & 1.10 & 0.90 & 0.96 & 0.89 \\
\hline 17. Crying & 0.75 & 0.95 & 0.82 & 0.95 & 0.80 & 0.94 & 0.81 & 0.95 \\
\hline 18. Sad & 0.80 & 0.90 & 1.06 & 0.93 & 1.19 & 0.90 & 1.07 & 0.92 \\
\hline 19. Dislike & 0.72 & 0.86 & 0.75 & 0.87 & 0.65 & 0.80 & 0.72 & 0.85 \\
\hline 20. Get going & 1.10 & 0.96 & 1.25 & 0.94 & 1.29 & 0.89 & 1.25 & 0.93 \\
\hline Total score & 17.9 & 8.30 & 20.8 & 8.7 & 21.8 & 7.90 & 20.8 & 8.5 \\
\hline
\end{tabular}

Table 4. Results for the exploratory factor analysis by age groups in Laotian adolescents

\begin{tabular}{|c|c|c|c|c|c|c|c|c|c|}
\hline \multirow{2}{*}{ Item } & \multicolumn{3}{|c|}{$\begin{array}{c}\text { Early Adolescents } \\
(11-14 \text { years })\end{array}$} & \multicolumn{3}{|c|}{$\begin{array}{l}\text { Late Adolescents } \\
\text { (15-19 years) }\end{array}$} & \multicolumn{3}{|c|}{$\begin{array}{l}\text { Young Adults } \\
(20-24 \text { years })\end{array}$} \\
\hline & $\mathrm{F} 1^{*}$ & $\mathbf{F} 2^{*}$ & $\mathrm{~F} 3^{*}$ & $\mathrm{~F} 1^{*}$ & $\mathrm{~F}^{*}{ }^{*}$ & $\mathrm{~F}^{*}$ & $\mathrm{~F} 1^{*}$ & $\mathrm{~F}^{*}$ & $\mathrm{~F}^{*}{ }^{*}$ \\
\hline 1. Bothered & 0 & & & $\bullet$ & & & 0 & & \\
\hline 2. Poor appetite & 0 & & & 0 & & & $\bullet$ & & \\
\hline 3. Blues & $\bullet$ & & & $\bullet$ & & & 0 & & \\
\hline 4. As good & & & 0 & & & 0 & & & $\bullet$ \\
\hline 5. Keeping mind & ○ & & & 0 & & & 0 & & \\
\hline 6. Depressed & & $\bullet$ & & $\bullet$ & & & $\bullet$ & & \\
\hline 7. Effort & & & $\bullet$ & & & 0 & & & $\bullet$ \\
\hline 8. Hopeful & & & 0 & & & ○ & & & 0 \\
\hline
\end{tabular}




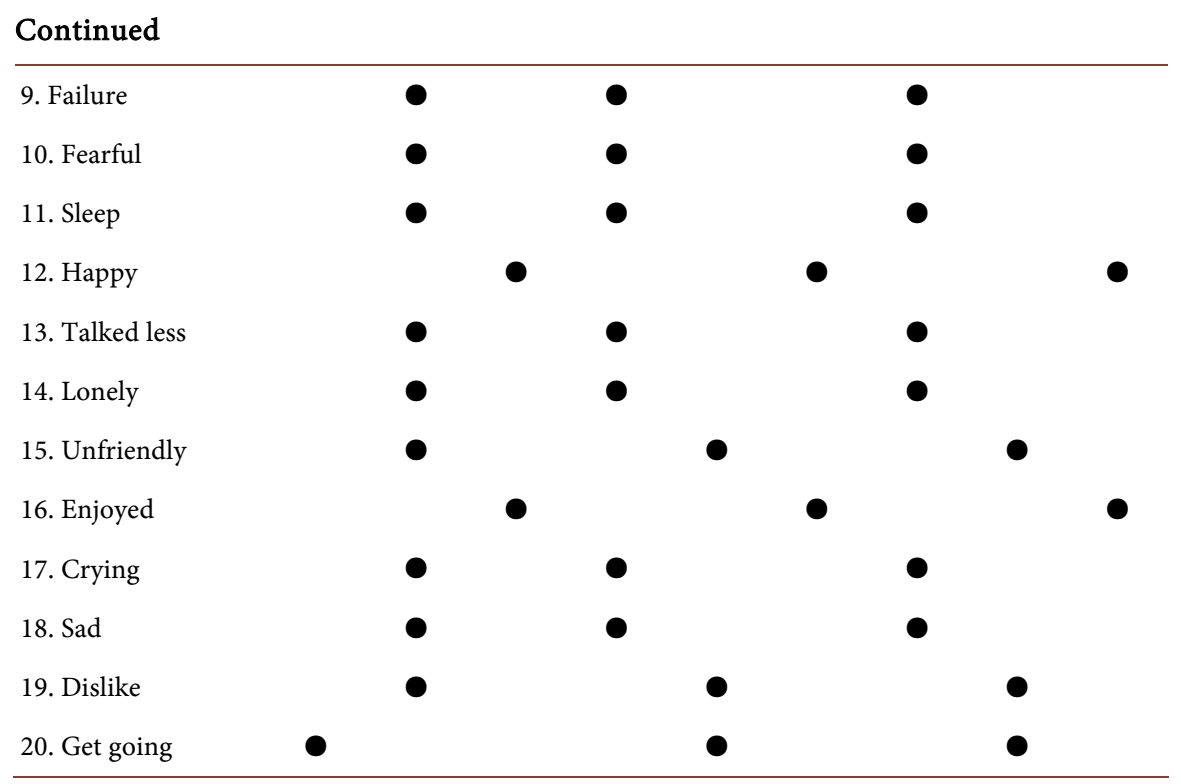

${ }^{\star}$ F1: Factor 1, F2: Factor 2, F3: Factor 3.

included ten items, while Factor 2 for late adolescents and young adults included three items. Factor 3 included the same five items for all three age groups.

\subsubsection{Results of Parallel Analysis}

Figure 1 shows the results of the parallel analysis. Based on this analysis, we assumed a two-factor model as a common model among the age groups and adopted a common solution for all three age groups.

\subsubsection{Results of Multi-Group Analysis}

Results of the multi-group analysis indicated a good fit $\left(\chi^{2}=5648.636, \mathrm{df}=619\right.$, $p<0.01, \mathrm{RMSEA}=0.059,90 \%$ confidence interval [CI]: $0.058-0.061), p<0.01$, $\mathrm{CFI}=0.912$, and SRMR $=0.058$ ). Based on the results of the multi-group analysis, we determined that a two-factor model was a common model among the age groups.

\subsubsection{Results of CFA}

As a result of CFA, we confirmed that the two-factor model, which had been identified in the multi-group analysis, was the best fitting structure for the aggregated data with all three age groups. The best-fitting structure comprised two factors: "Negative affect" (F1) and "Positive affect" (F2) (Table 5). The first factor contained 15 items, and it had to combine items indicating "Depressed affect," "Somatic and retarded activity," and "Interpersonal." The second factor contained five items: "Positive affect" and "Somatic and retarded activity." The results of the CFA with the two-factor model indicated a good fit $\left(\chi^{2}=5808.733\right.$, $\mathrm{df}=169, p<0.01, \mathrm{RMSEA}=0.066,90 \%$ confidence interval $[\mathrm{CI}]: 0.065-0.068)$, $p=0.01$, CFI $=0.911$, and SRMR $=0.056$ ). Cronbach's alpha coefficient was 0.81 . Regarding factor correlations, there was a significant correlation between factor scores for "Negative affect" and "Positive affect" $(r=0.137, S E=0.020, p$ 




Figure 1. Results of parallel analysis with aggregated data across the three age groups.

Table 5. Solution for the confirmatory factor analysis in Laotian adolescents.

\begin{tabular}{lcc}
\hline & Factor 1: Negative Affects & Factor 2: Positive Affects \\
\hline 1. Bothered & $0.475^{*}$ & 0.016 \\
2. Poor appetite & $0.482^{\star}$ & 0.004 \\
3. Blues & $0.594^{*}$ & 0.000 \\
5. Keeping mind & $0.462^{*}$ & $0.139^{*}$ \\
6. Depressed & $0.733^{*}$ & 0.020 \\
9. Failure & $0.615^{*}$ & $0.037^{*}$ \\
10. Fearful & $0.555^{*}$ & $0.086^{*}$ \\
11. Sleep & $0.570^{*}$ & $0.037^{*}$ \\
13. Talked less & $0.448^{*}$ & $0.056^{*}$ \\
14. Lonely & $0.734^{*}$ & 0.017 \\
17. Crying & $0.598^{*}$ & 0.021 \\
18. Sad & $0.766^{*}$ & 0.004 \\
20. Get going & $0.555^{*}$ & $0.034^{*}$ \\
15. Unfriendly & $0.578^{*}$ & $0.083^{*}$ \\
19. Dislike & $0.628^{*}$ & $0.098^{*}$ \\
7. Effort & $0.158^{*}$ & $0.544^{*}$ \\
4. As good_(r) & 0.013 & $0.464^{*}$ \\
8. Hopeful_(r) & $0.063^{*}$ & $0.643^{*}$ \\
12. Happy_(r) & $-0.124^{*}$ & $0.568^{*}$ \\
16. Enjoyed_(r) & $-0.264^{*}$ & $0.419^{*}$ \\
\hline & & 09 \\
\hline
\end{tabular}

${ }^{1}$ Fit indices: Chi-Square Test of Model Fit (Value: 5808.733, Degrees of Freedom: 169, $p<0.01$ ), RMSEA (Estimate 0.066, 90 Percent C.I.: 0.065 - 0.068, Probability RMSEA $\leq$ 0.05: $p<0.01$ ), SRMR: 0.056, CFI: $0.911 .{ }^{2}(\mathrm{r})$ : reverse-scored item. ${ }^{3 *}$ significant at $5 \%$ level.

$<0.05)$. Therefore, we concluded that the developed model could be applied as a scale for depressive symptoms among Laotian adolescents.

Although the Laotian adult model (Tomokawa et al., 2018) consists of three factors, the Laotian adolescent model consisted of two factors. The "Effort" item loaded on the "Somatic and retarded activity" factor in Radloff's model (Radloff, 
1977), while it was excluded in the Laotian adult model and loaded on the "Positive affect" factor in the Laotian adolescent model. Moreover, "Depressed affect," "Somatic and retarded activity," and "Interpersonal" items were combined into one factor ("Negative affect") in the Laotian adolescent model.

\section{Discussion}

This study developed a CES-D for Laotian adolescents and examined its reliability, validity, and factorial properties. As a result, we found a two-factor structure consisting of "Negative affect" and "Positive affect" as the best fitting model for Laotian adolescents.

In the following discussion, we focus on the differences between the Laotian adolescent model, the Laotian adult model, Radloff's model, and other adolescent models in Asia.

We identified three differences between the Laotian adult model and the Laotian adolescent model. First, the Laotian adult model comprises three factors: "Sadness/loneliness," "Psychosomatic symptoms," and "Lack of positive affect" (Tomokawa et al., 2018), while the Laotian adolescent model consists of two factors. Second, interpersonal items behaved differently in the two models. "Dislike" and "Unfriendly" loaded on "Negative" items in the adolescent model, but "Dislike" loaded on "Sadness/loneliness," and "Unfriendly" was excluded from the adult model. Third, the "Effort" item, indicating "Somatic and retarded activity," was combined with the items "Happy," "Enjoyed," "Hopeful," and "As good as" in the Laotian adolescent model, and the aggregate of these items formed "Positive affect," as in Radloff's model, but unlike the adult model in which "As good as" was excluded because of its low loading. This may be why the Laotian adolescent model developed in this study consisted of factors similar to the Depression Self-Rating Scale for Children (DSRS-C), which was developed for children rather than for adults (Birleson, 1981).

A possible reason why the Laotian adolescent model is composed of two factors, namely "Negative affect" and "Positive affect," is that, in general, adults' somatization results in physical symptoms as a result of suppression of mental depressive mood. On the other hand, in adolescents, mental functioning and sociality are still immature and developing, and thus mental depressive mood and physical symptoms often remain undifferentiated or not fully differentiated (Denda, 2002). In addition, it is thought that $\mathrm{f}$ developmental factors and socio-cultural factors as well as the nature of the event that causes depression (the stressor) differentiate such experiences of depression (Falicov, 2003). Other possible reasons for the differences between the adult and adolescent model are that the translation of the CES-D for adolescents was improved compared with the model for adults. Besides, the size of the adolescent sample was much larger than that of the adult sample.

In the comparison between Radloff's model and the Laotian adolescent model, we identified three differences. First, Radloff's model comprises four factors, 
whereas the Laotian adolescent model comprises two factors. Second, items in "Depressive affect," "Somatic and retarded activity," and "Interpersonal" were distinguished as individual factors in Radloff's model, while items in these three factors were combined into one factor ("Negative affect") in the Laotian adolescent model. Third, the Laotian adolescent model combined the "Effort" item that indicates "Somatic and retarded activity" with other items indicating "Positive affect" as one factor.

As for the second point, the lack of distinction between "Depressed affect" items and "Somatic and retarded activity" items is congruent with the findings reported in several previous studies with adolescent samples in Asia (Edman et al., 1999; Ghazali, Elklit, Balang, \& Chen, 2016; Heo, Choi, Yu, \& Nam, 2018; Yen, Robins, \& Lin, 2000; Ying et al., 2000). In addition, the Laotian adolescent samples did not distinguish "Unfriendly" and "Dislike" as "Interpersonal." These results supported the findings of previous studies with samples of Filipino American adolescents (Edman et al., 1999), Taiwanese adolescents (Cheng, Yen, Ko, \& Yen, 2012), Mainland Chinese adolescents (Wang et al., 2013), Malaysian adolescents (Ghazali, Elklit, Balang, \& Chen, 2016), and Korean adolescents (Heo, Choi, Yu, \& Nam, 2018). These previous studies could not distinguish the "Depressed affect" and "Somatic and retarded activity" items from the interpersonal items.

Moreover, regarding the third point, the "Effort" item indicating "Somatic and retarded activity" loaded on "Positive affect" in the Laotian adolescent model. This is one of Laotian CES-D models' features, although we cannot find any explanation based on the available literature. As a possible interpretation of the reason for the different loading of "Effort," the meaning of the "Effort" item may have a positive nuance because of the cultural and expressive characteristics of the Lao language. When developing the CES-D in a language other than English, it is necessary to carefully consider the meaning and nuances of every word, phrase, sentence, expression, and cultural context behind the language.

Besides, a possible reason for the overlap between "Depressive affect" and "Somatic retarded activity" items in the adolescent model is that Laotians may tend to regard somatic symptoms as depressive affective symptoms and report them in such a manner. What is more, Laotian people may show somatic symptoms and related psychological symptoms, as has been confirmed by other studies in Asian samples (Parker, Cheah, \& Roy, 2001; Ryder et al., 2008), including the Laotian adult population (Tomokawa et al., 2018).

There are several limitations to this study. First, the sample covered only three areas of Lao PDR, and none of the three were remote areas. Therefore, the sample is not representative of the general Laotian adolescent population. In general, adolescents are at higher risk for developing mental health disorders because of their fragile living conditions, stigma, discrimination, or exclusion because of belonging to minority ethnic backgrounds and minority sexual orientation status or other discriminated groups, or lack of access to quality support and ser- 
vices (World Health Organization, 2020). Therefore, it is necessary to examine if the developed CES-D applies to Laotian adolescents who live in remote areas or under other living conditions, including adolescents from disadvantaged backgrounds such as belonging to minority groups. Second, it is necessary to clarify depressive tendencies in Laotian adolescents and factors related to these tendencies in future studies. A previous comparative study among adolescent in Laos, Mongolia, Nepal, and Sri Lanka mentioned that the adolescents who had reported smoking and consuming alcohol and woman students were more likely to report distress in Laos (Lee et al., 2019). In addition, multiple factors ranging from socioeconomic problems to the poor quality of children's home life or relationships with friends and guardians are recognized as risk factors for mental health problems (World Health Organization, 2020). Clarifying factors related to adolescent mental health in the Laotian context will contribute to developing effective mental health programs in Laos. Although this study has above-mentioned limitations, the CES-D model developed in this study will help grasp the state of mental health among adolescents which has not been enough studied so far in Lao PDR and thus, enable to implement required early interventions. In addition, the results from this study can contribute to improving teaching content relating to children's mental health in teacher training courses in Laos.

\section{Conclusion}

This study developed a Laotian version of the CES-D for adolescents, and examined its reliability and validity as well as factorial properties. As a result of this study, we determined a best-fitting structure comprising two factors: "Negative affect" and "Positive affect". "Effort" items loaded on the "Somatic and retarded activity" factor in the original model but loaded on the "Positive affect" factor in the adolescent model. "Depressed affect", "Somatic and retarded activity" and "Interpersonal" items were combined into the "Negative affect" factor in the adolescent model.

\section{Acknowledgements}

We would like to thank the students in the provinces of Luangprabang, Savannakhet, and Champasak who participated in this research. This research was funded by JSPS KAKENHI Grant Number JP 18K19671, and Grant from National Centre for Global Health and Medicine (30-4).

\section{Conflicts of Interest}

The authors declare no conflicts of interest regarding the publication of this paper.

\section{References}

Asakura, T., Hein, M., Tomokawa, S., Moji, K., \& Kobayashi, J. (2015). The Ecosystem Approach to Health Is Promising Strategy in International Development: Lessons from 
Japan and Laos. Globalization and Health, 11, 3. https://doi.org/10.1186/s12992-015-0093-0

Beck, A. T., Ward, C. H., Mendelson, M., Mock, J., \& Febraugh, J. (1961). An Inventory for Measuring Depression. Archives of General Psychiatry, 4, 561-571. https://doi.org/10.1001/archpsyc.1961.01710120031004

Bentler, P. M. (1990). Comparative Fit Indexes in Structural Models. Psychological Bulletin, 107, 238-246. https://doi.org/10.1037/0033-2909.107.2.238

Birleson, P. (1981). The Validity of Depressive Disorder in Childhood and the Development of a Self-Rating Scale: A Research Report. Journal of Child Psychology and Psychiatry, 22, 73-88. https://doi.org/10.1111/j.1469-7610.1981.tb00533.x

Browne, M. W., \& Cudeck, R. (1993). Alternative Ways of Assessing Model Fit. In K. A. Bollen, \& J. S. Long (Eds.), Testing Structural Equation Models (pp. 136-162). Newbury Park, CA: Sage.

Cheng, C. P., Yen, C. F., Ko, C. H., \& Yen, J. Y. (2012). Factor Structure of the Center for Epidemiologic Studies Depression Scale in Taiwanese Adolescents. Comprehensive Psychiatry, 53, 299-307. https://doi.org/10.1016/j.comppsych.2011.04.056

Crockett, L. J, Randall, B. A., Shen, Y. L., Russell, S. T., \& Driscoll, A. K. (2005). Measurement Equivalence of the Center for Epidemiological Studies Depression Scale for Latino and Anglo Adolescents: A National Study. Journal of Consulting and Clinical Psychology, 73, 47-58. https://doi.org/10.1037/0022-006X.73.1.47

Denda, K. (2002). Kodomo no Utsubyou (Depression in Children) (pp. 14-17). Tokyo: Kongo-syuppan. (In Japanese)

Dick, R. W., Beals, J., Keane, E. M., \& Manson, S. (1994). Factorial Structure of the CES-D among American Indian Adolescents. Journal of Adolescence, 17, 73-79. https://doi.org/10.1006/jado.1994.1007

Edman, J. L., Danko, G. P., Andrade, N., McArdle, J. J., Foster, J., \& Glipa, J. (1999). Factor Structure of the CES-D (Center for Epidemiologic Studies Depression Scale) among Filipino-American Adolescents. Social Psychiatry and Psychiatric Epidemiology, 34, 211-215. https://doi.org/10.1007/s001270050135

Falicov, C. J. (2003). Culture, Society and Gender in Depression. Journal of Family Therapy, 25, 371-387. https://doi.org/10.1111/1467-6427.00256

Ghazali, S. R., Elklit, A., Balang, R. V., \& Chen, Y. Y. (2016). Concurrent Validity and Exploratory Factors Analysis of the Malay Version of Center for Epidemiologic Studies-Depression Scale (CESD) among Malaysian Adolescents. ASEAN Journal of Psychiatry, 17, 71-78.

Heo, E. H., Choi, K. S., Yu, J. C., \& Nam, J. A. (2018). Validation of the Center for Epidemiological Studies Depression Scale among Korean Adolescents. Psychiatry Investigation, 15, 124-132. https://doi.org/10.30773/pi.2017.07.19

Hu, L., \& Bentler, P. M. (1999). Cutoff Criteria for Fit Indexes in Covariance Structure Analysis: Conventional Criteria versus New Alternatives. Structural Equation Modeling, 6, 1-55. https://doi.org/10.1080/10705519909540118

Kessler, R. C., Amminger, G. P., Aguilar-Gaxiola S., Alonso J., Lee S., \& Ustün T. B. (2007a). Age of Onset of Mental Disorders: A Review of Recent Literature. Current Opinion in Psychiatry, 20, 359-364. https://doi.org/10.1097/YCO.0b013e32816ebc8c

Kessler, R. C., Angermeyer, M., Anthony, J. C., de Graaf, R., Demyttenaere, K., \& Gasquet, I. (2007b). Lifetime Prevalence and Age-of-Onset Distributions of Mental Disorders in the World Health Organization's World Mental Health Survey Initiative. World Psychiatry, 6, 168-176. 
Kieling, C., Baker-Henningham, H., Belfer, M., Conti, G., Ertem, I., Omigbodun, O. et al. (2011). Child and Adolescent Mental Health Worldwide: Evidence for Action. The Lancet, 378, 1515-1525. https://doi.org/10.1016/S0140-6736(11)60827-1

Laos Statistical Information Service (2019). Population Distribution, by Sex and Age Group. https://laosis.lsb.gov.la/tblInfo/TblInfoList.do?fbclid=IwAR1Rx 2fzFhNpoXS9ca1BpA d57ybHeuMhSxtUR9weTz0ONFMqvkvJTumKmo

Lee, H., Lee, E. Y., Greene, B., \& Shin, Y. (2019). Psychological Distress among Adolescents in Laos, Mongolia, Nepal, and Sri Lanka. Asian Nursing Research, 13, 147-153. https://doi.org/10.1016/j.anr.2019.04.001

Li, H. C., Chung, O. K., \& Ho, K. Y. (2010). Center for Epidemiologic Studies Depression Scale for Children: Psychometric Testing of the Chinese Version. Journal of Advanced Nursing, 66, 2582-2591. https://doi.org/10.1111/j.1365-2648.2010.05440.x

Ministry of Education \& Ministry of Health, Lao PDR (2010). National School Health Policy (pp. 1-15). Vientiane: Ministry of Education and Ministry of Health, Lao PDR.

Parker, G., Cheah, Y. C., \& Roy, K. (2001). Do the Chinese Somatize Depression? A Cross-Cultural Study. Social Psychiatry and Psychiatric Epidemiology, 36, 287-293. https://doi.org/10.1007/s001270170046

Phanthavong, P., Naphayvong, P., \& Reinharz, D. (2015). Depression among Last-Year High School Students in Vientiane, Capital City of Lao PDR. Asia-Pacific Journal of Public Health, 27, 1995-1998. https://doi.org/10.1177/1010539513489135

Radloff, S. L. (1977). The CES-D Scale: A Self-Report Depression Scale for Research in the General Population. Applied Psychological Measurement, 1, 385-401. https://doi.org/10.1177/014662167700100306

Ryder, A. G., Yang, J., Zhu, X., Yao, S., Yi, J., \& Heine, S. J. (2008). The Cultural Shaping of Depression: Somatic Symptoms in China, Psychological Symptoms in North America? Journal of Abnormal Psychology, 117, 300-313. https://doi.org/10.1037/0021-843X.117.2.300

Sawyer, S. M., Azzopardi, P. S., Wickremarathne, D., \& Patton, G. C. (2018). The Age of Adolescence. The Lancet Child and Adolescent Health, 2, 223-228. https://doi.org/10.1016/S2352-4642(18)30022-1

Tomokawa, S., Asakura, T., Keosada, N., Bouasangthong, V., Souvanhxay, V., Navamal, P. et al. (2020). Introducing Ecohealth Education in a Teacher Training Institute in Lao PDR: A Case Study. Health Promotion International, daaa100.

https://doi.org/10.1093/heapro/daaa100

Tomokawa, S., Asakura, T., Keosada, N., Miyake, K., Khamheang, U., \& Moji, K. (2018). Preliminary Study of the Reliability and Validity of the Center for Epidemiologic Studies Depression Scale in Lao PDR. Psychology, 9, 2396-2410.

https://doi.org/10.4236/psych.2018.910137

United Nations Children's Fund (2011). The State of the World's Children 2011: Adolescence-An Age of Opportunity. New York: United Nations Children's Fund. https://www.unicef.org/sowc2011/pdfs/SOWC-2011-Main-Report EN 02092011.pdf https://doi.org/10.18356/7f132111-en

Wang, M., Armour, C., Wu, Y., Ren, F., Zhu, X., \& Yao, S. (2013). Factor Structure of the CES-D and Measurement Invariance across Gender in Mainland Chinese Adolescents. Journal of Clinical Psychology, 69, 966-979. https://doi.org/10.1002/jclp.21978

World Bank (n.d.). World Bank Open Data, School Enrollment, Secondary (\% Net) Lao $P D R$. 
https://data.worldbank.org/indicator/SE.SEC.NENR?end=2018\&locations=LA\&start=2 $\underline{000}$

World Health Organization (2014). Health for the World's Adolescents: A Second Chance in the Second Decade (Online Report). https://apps.who.int/adolescent/second-decade

World Health Organization (2017). Depression and Other Common Mental Disorders: Global Health Estimates. Geneva: World Health Organization. http://apps.who.int/iris/bitstream/10665/254610/1/WHO-MSD-MER-2017.2-eng.pdf

World Health Organization (2018). Adolescents: Health Risks and Solutions. https://www.who.int/news-room/fact-sheets/detail/adolescents-health-risks-and-soluti ons

World Health Organization (2020). WHO Adolescent Health Key Fact. https://www.who.int/news-room/fact-sheets/detail/adolescent-mental-health

World Health Organization (n.d.). Very Young Adolescents. https://www.who.int/reproductivehealth/topics/adolescence/very young ados/en

Yen, S., Robins, C. J., \& Lin, N. (2000). A Cross-Cultural Comparison of Depressive Symptom Manifestation: China and the United States. Journal of Consulting and Clinical Psychology, 68, 993-999. https://doi.org/10.1037/0022-006X.68.6.993

Ying, Y. W., Lee, P. A., Tsai, J. L., Yeh, Y. Y., \& Huang, J. S. (2000). The Conception of Depression in Chinese American College Students. Cultural Diversity and Ethnic Minority Psychology, 6, 183-195. https://doi.org/10.1037/1099-9809.6.2.183 